\title{
Spectrophotometric determination of copper as copper Piperazine
}

\author{
Ch. Kavitha ${ }^{1}$, M. Sarath Babu ${ }^{2, *}$, K. Saraswathi ${ }^{3}$ \\ ${ }^{1}$ Depatrment of Chemistry, V. R. Siddhartha Engineering College, Kanuru-520007, A. P., India \\ ${ }^{2}$ MIC College of Technology, Kanchikacherla-521180, A. P., India \\ ${ }^{3} \mathrm{NRI}$ Institute of Technology, Nunna-521212, A. P., India \\ *E-mail address: sarathmogallapu@gmail.com
}

\begin{abstract}
Spectrophotometric method for determination of $\mathrm{Cu}(\mathrm{II})$ in the trace quantities was developed by using piperazine as ligand in ammonium acetate medium. The Procedure developed was applied for the estimation $\mathrm{Cu}(\mathrm{II})$ in microgram quantities in the samples of alloys and the method was found to be simple, rapid and comparable to routine analytical methods for trace level analysis of metal ions in environmental samples in any laboratory where sophisticated and expensive instruments are not available. UV visible spectrophotometer is cost effective and available in almost all laboratories. The complexes of piperazine in aqueous solutions are not reported so far and this is the first attempt in this area of spectrophotometric analysis.
\end{abstract}

Keywords: Spectophotometry; $\mathrm{Cu}(\mathrm{II})$; piperazine

\section{INTRODUCTION}

Copper is one of the several metals that play an important role in the biological systems. Copper occurs naturally in many vegetables, meat and grains.

Increased copper levels in drinking water may also cause increase in lead levels which in turn may be associated with liver damage and kidney diseases [1]. Copper kills a variety of potentially harmful pathogens. On Feb 29, 2008 the United States EPA registered 275 alloys containing greater than $65 \%$ nominal copper content as anti-microbial materials [2].

In view of the important role played by copper in biological and environmental areas, an attempt has been made to study copper through spectrophotometric determination by using piperazine as a reagent.

The method was also applied to samples of alloys and results were co-related with the standard samples [3].

\section{MATERIALS AND METHODS}

Copper reacts with piperazine forming blue coloured complex in ammonium acetate and shows maximum absorption at $667 \mathrm{~nm}$. Since the $\mathrm{Cu}$-piperazine complex has maximum 
absorption at $667 \mathrm{~nm}$, the experiment was carried out at the same wavelength. SL 191 double beam UV - Visible spectrophotometer was used for recording absorption spectrum of the solutions. Digital pH meter ELICO LI 127 provided with temperature control knob was used throughout the work. Analytical grade chemicals and double distilled water have been used in all the experiments.

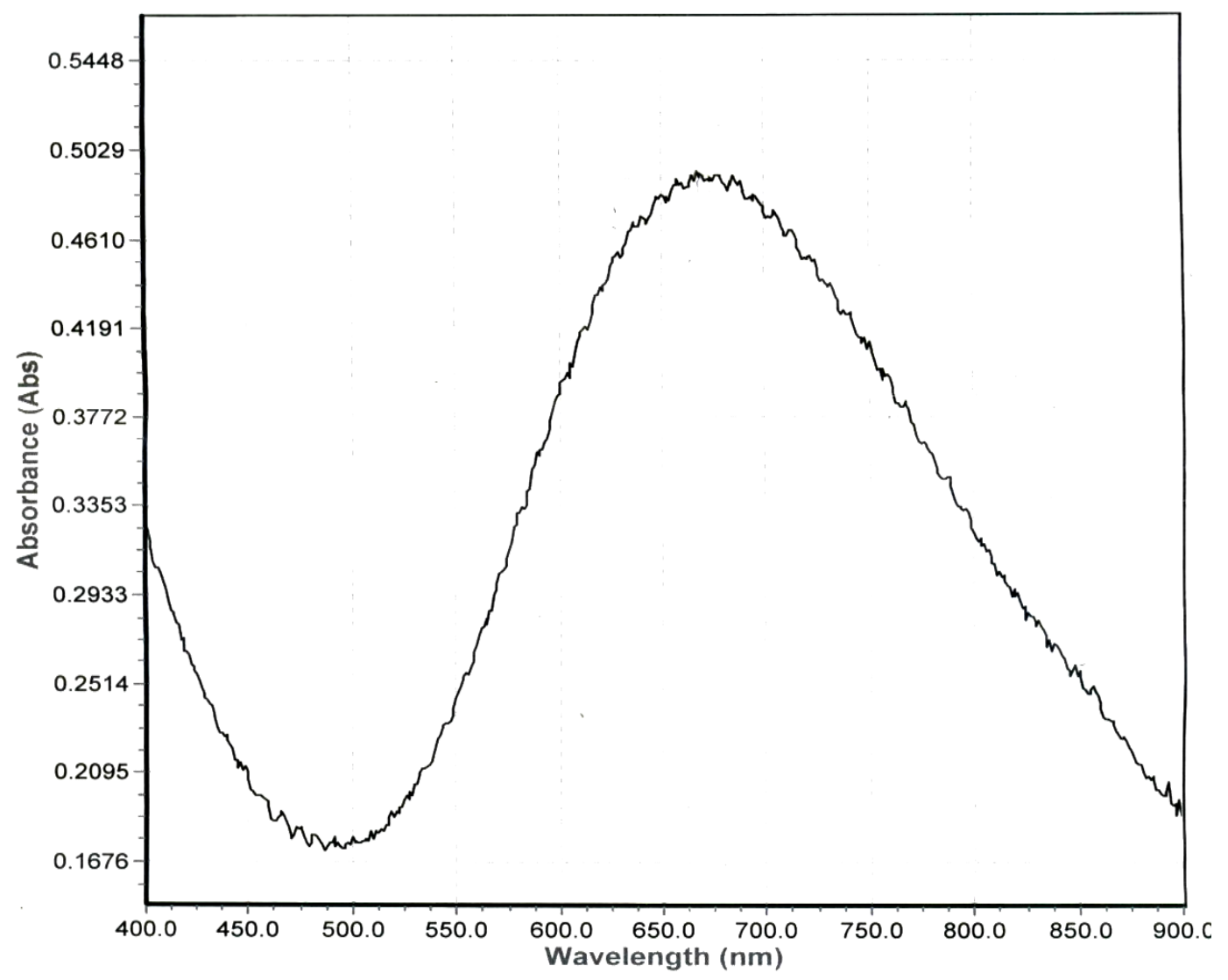

Fig. 1. Ammonium acetate solution shows maximum absorbance.

\section{RESULTS AND DISCUSSION}

The experimental conditions for quantitative results have been developed by studying the effect of various parameters that follow.

\section{Effect of ammonium acetate:}

By keeping all the factors constant the volume of ammonium acetate solution was changed from $0.5 \mathrm{ml}$ to $3.0 \mathrm{ml}$ and the subsequent effect was noted. It was observed that $1 \mathrm{ml}$ of $3 \mathrm{M}$ ammonium acetate solution shows maximum absorbance followed by decrease in the same. The complex is appreciably stable in this medium at $1 \mathrm{ml}$ as there is no change in the absorbance even after a day i.e., 24 hours (Fig. 1).

Effect of reagent concentration:

The effect of reagent concentration on cu-piperazine complex was studied by maintaining a metal ion concentration of $2 \mathrm{ml}$ of $0.05 \mathrm{M}, 2 \mathrm{ml}$ of $3 \mathrm{M} \mathrm{CH}_{3} \mathrm{COONH}_{4}$ and by 
varying the reagent concentration between $0.5 \mathrm{ml}$ to $5.0 \mathrm{ml}$ of $0.05 \mathrm{M}$ piperazine and the absorbance values were noted.

Appilacability of Beer's Law:

A set of test tubes are taken and into each test tube, $2 \mathrm{ml}$ of $0.05 \mathrm{M}$ reagent solution, 1 $\mathrm{ml}$ of $3 \mathrm{M}$ ammonium acetate and different known concentration of $\mathrm{Cu}$ (II) solution are transferred. The total volume was made upto $10 \mathrm{ml}$ by adding double distilled water. The solutions were shaken for a minute and the absorbance values were measured at $667 \mathrm{~nm}$. A graph is plotted between volume of $\mathrm{Cu}$ (II) in milliliters and absorbance values (Fig. 2).

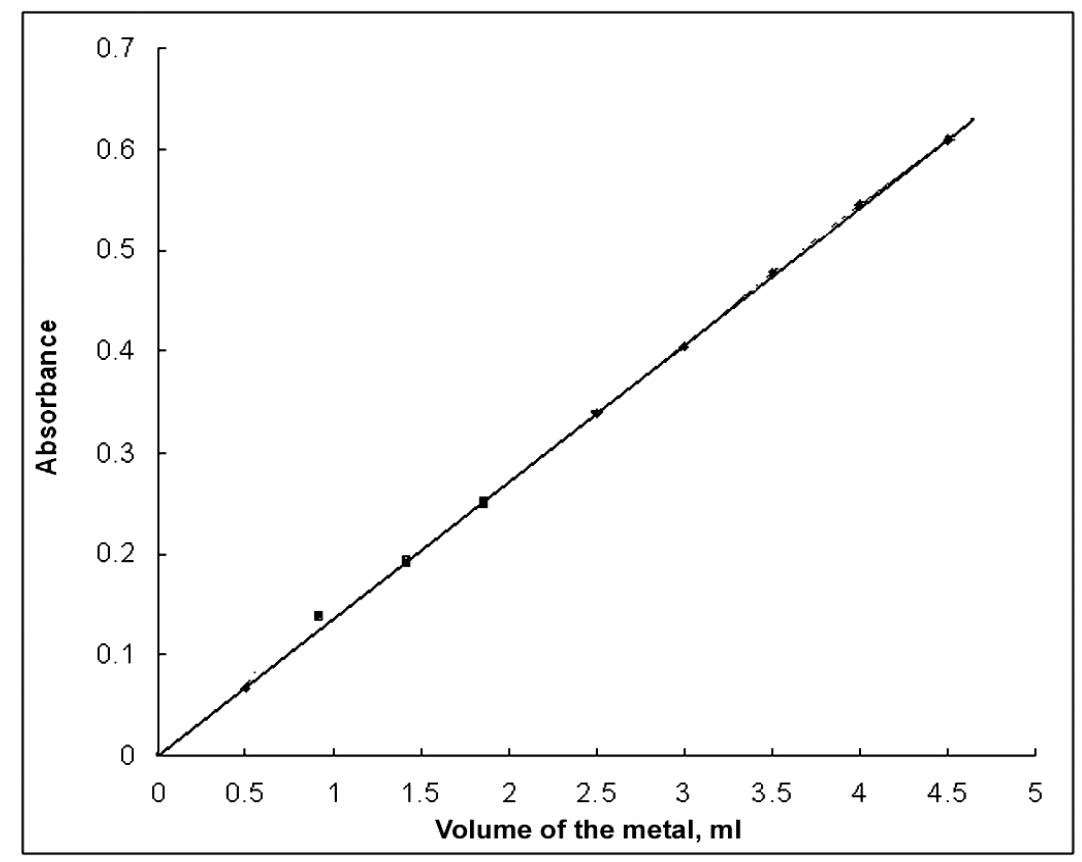

Fig. 2. Applicability of Beer's Law.

\section{Job's method of continous variation:}

A Series of solutions of varying mole fractions of $\mathrm{Cu}(\mathrm{II})$ and piperazine were prepared keeping the total volume constant. In each case $1 \mathrm{ml}$ of $3 \mathrm{M}$ ammonium acetate was added and the final volume was made up to $10 \mathrm{ml}$ with distilled water. The test tubes were shaken well and the absorbance values in each case were measured at $667 \mathrm{~nm}$. A graph was plotted between absorption and mole fraction of the ligand and from the graph it is observed that two moles of copper chelates with 4 moles of piperazine indicating that the compositions of the complex as 1:2 in Cu-piperazine complex [4,5].

\section{Mole ratio method:}

To $1.0 \mathrm{ml}$ of $0.05 \mathrm{M}$ cupric solution, $1 \mathrm{ml}$ of $3 \mathrm{M}$ ammonium acetate $(3 \mathrm{M})$ and required volume of piperazine solution were added and shaken well. The absorbance of the complex was measured at $667 \mathrm{~nm}$. The experiment was repeated with different volumes of the reagent ranging from $0.5 \mathrm{ml}$ to $8 \mathrm{ml}$ and the absorbance values were noted. A graph was plotted between volume of ligand and absorbance and it is observed that 1 mole of copper chelates with 2 moles of piperazine (Fig. 3). 


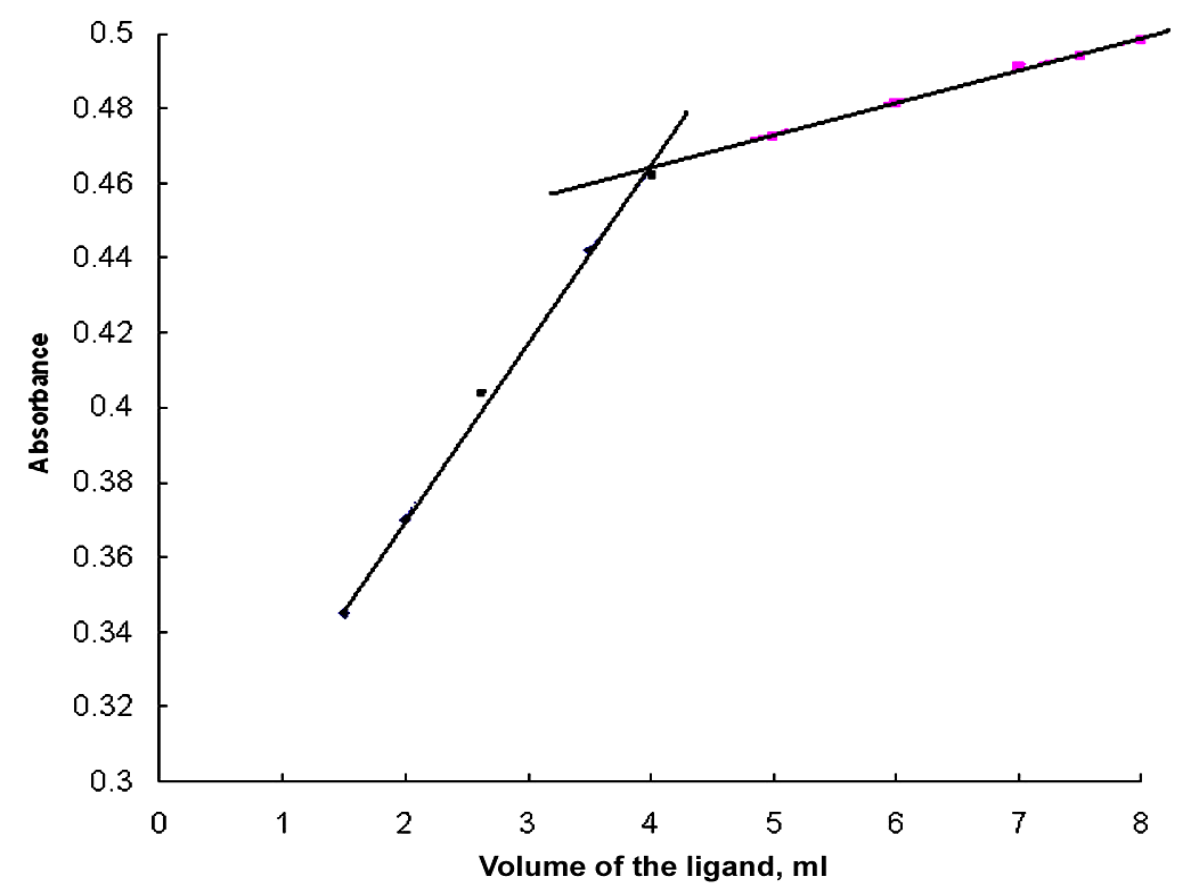

Fig. 3. Mole Ratio Method.

Asmus method:

The experimental part for Asmus method was same as the procedure followed in mole ratio method. A linear plot was obtained between $1 / \mathrm{m}$ and $1 / \mathrm{v}^{2}$ confirming the ratio of the metal to ligand as 1:2. The instability constant of the copper complex calculated is found to be $5.95 \mathrm{X}$

Application of the method:

Piperazine: $0.05 \mathrm{M}$

Ammonium acetate: $1 \mathrm{ml}$ of $3 \mathrm{M}$

Certified amounts [6-8] (\%) Cu: 67.4, Zn:28.6, Sn:1.09, Pb:2.23, Fe:0.30, Ni: 0.33, P: 0.01.

Table 1. Determination of $\mathrm{Cu}(\mathrm{II})$ in alloys of brass sample.

\begin{tabular}{|c|c|c|}
\hline Sample & S. No. & \% of copper found \\
\hline \multirow{3}{*}{ I } & i & 67.20 \\
\cline { 2 - 3 } & ii & 67.30 \\
\cline { 2 - 3 } & iii & 67.10 \\
\cline { 2 - 3 } & iv & 67.04 \\
\hline
\end{tabular}

Average: 67.25

$\%$ of Error: 0.22 


\section{CONCLUSION}

Copper can be conveniently estimated in its trace amounts as Copper Piperazine by Spectrophotometric method. This method developed is simple, accurate and effective. Conditions like effect of $\mathrm{pH}$, reagent concentration can be fixed by studying them in detail. The composition of the complex formed by copper can also be established by studying the same. The method developed can be successfully applied to estimation of copper in various samples of alloys like brass, bronze etc. This method also can be tried for other environmental samples like water, industrial waste water etc.

\section{References}

[1] Smith William F., Hashemi Javad, Foundations of Materials Science and Engineering, McGraw-Hill Professional, 2003, p. 223.

[2] Hammond C. R., The Elements, in Handbook of Chemistry and Physics 81st edition, CRC Press, 2004.

[3] Ackerman R., A Bottom In Sight For Copper, Forbes, 02-04-2009.

[4] "CSA - Discovery Guides, A Brief History of Copper", Csa.com. Retrieved 2008-09-12.

[5] Lynch Martin, Mining in World History, 2004-04-15, pp. 60.

[6] "Gold Jewellery Alloys", World Gold Council. Retrieved, 2009-06-06.

[7] "EPA registers copper-containing alloy products", US Environmental Protection Agency, Retrieved, 2009-06-06.

[8] "Pesticide Information Profile for Copper Sulfate", Cornell University, Retrieved 2008- 07-10. 